\title{
A POLÍTICA DE BÔNUS PARA OS PROFISSIONAIS DA EDUCAÇÃO NO ESTADO DO ACRE: CONCEPÇÃO E NORMATIZAÇÃO
}

Lúcia de Fátima Melo Débora Maria Pinto Braidi ${ }^{(*)}$

\section{INTRODUÇÃO}

O estudo em questão analisa uma das políticas que compõem o conjunto de ações propostas pela reforma educacional em curso no Estado do Acre cujo marco inaugural se dá com a ascensão ao poder de uma Frente de Partidos denominada Popular, capitaneada pelo Partido dos Trabalhadores no ano de $1999^{1}$. Trata-se da política de pagamento de bônus dirigida aos profissionais do magistério acriano, estabelecida por intermédio de decretos e Leis Complementares. A análise coloca em relevo o contexto em que a política foi concedida, como vem sendo implementada e os conflitos que tem ensejado.

Resumidamente é possível afirmar que em âmbito mais geral este contexto é marcado por transformações oriundas das mudanças nas relações sociais de produção, no processo de reestruturação produtiva e na chamada reforma do Estado, tendo como um dos seus eixos no campo das políticas educativas o surgimento de uma nova regulação ${ }^{2}$ que emergiu em consequência do ciclo de reformas que muitos países conheceram nos seus sistemas educacionais, a partir dos anos de 1990. Este cenário vai dá origem a políticas educacionais caracterizadas, entre outras questões, pela responsabilização docente nos resultados alcançados por suas escolas nos índices oriundos de processos de avaliações externas.

A origem das análises presente neste artigo integra questões suscitadas em projetos institucionais de pesquisa concluído ${ }^{3}$ e em andamento ${ }^{4}$ e em dissertação de mestrado em processo

\footnotetext{
${ }^{(*)}$ Lúcia de Fátima Melo. Professora do Programa de Pós-Graduação em Educação da Universidade Federal do Acre. Débora Maria Pinto Braidi. Pedagoga e Mestranda em Educação Programa de Pós-Graduação em Educação da Universidade Federal do Acre.

${ }^{1}$ Uma visão mais detalhada sobre a Reforma do Sistema Educacional acriano pode ser visto em Melo (2010) e Damasceno (2010).

2 Para melhor compreensão do conceito de Regulação e suas implicações na esfera da educação recomendamos os trabalhos de Barroso (2005) e Oliveira (2005).

3 Trata-se do Projeto de Pesquisa: "As exigências de performatividade e seus impactos no trabalho de Diretores escolares no Município de Rio Branco-Acre”.
} 
final de construção. O estudo integra também o conjunto das atividades de investigação desenvolvidas no âmbito do Grupo de Estudos e Pesquisas em Políticas Educacionais, Gestão Escolar, Trabalho e Formação Docente (GEPPEAC/UFAC).

Tendo como referência estes aspectos mais amplos, este artigo encontra-se dividido em duas partes. Na primeira parte, ancorado na literatura o texto analisa a relação existente entre avaliação de sistemas e responsabilização com as concepções que orientam os processos avaliativos de desempenho docente, impulsionado em última instância pela chamada Nova Gestão Pública (NGP) que se caracteriza por uma racionalidade em que princípios como a autonomia escolar, a prestação de contas, a gestão baseada em resultados e a liberdade de escolha têm interferido profundamente na regulação dos sistemas educativos.

Na segunda parte, utilizando-se da base legal que fundamenta a política, são apresentados e analisados as leis complementares e os decretos regulamentares que sustentam legalmente a política de bônus acriana consubstanciada no Prêmio Anual de Valorização e Desenvolvimento Profissional, atualmente designado com a sigla de VDP.

Ao final procura-se evidenciar as principais alterações desta política de governo desde a sua concepção até sua efetivação como uma política de Estado para onde tem caminhado, apontando suas limitações.

\section{O BÔNUS COMO POLÍTICA DE VALORIZAÇÃO DOS PROFISSIONAIS DA EDUCAÇÃO: CONCEPÇÃO}

É consenso entre os estudiosos de política educacional que a realização de provas padronizadas internacionalmente, nacionalmente e subnacionalmente, desenvolvidas como instrumento para mensurar a aprendizagem dos alunos, tem crescido ao longo dos anos (SOUZA e OLIVEIRA, 2010).

No Brasil, contudo, existem pouquíssimos estudos avaliativos com desdobramentos e consequências práticas no aprimoramento da gestão de políticas públicas. A política de pagamento de bônus também segue esta tendência, ou seja, carece de estudos que evidenciem, que desvele qual tem sido o resultado prático na melhoria do ensino de uma política como esta que mobiliza recursos

4 Projetos de pesquisa intitulados: "O trabalho, a identidade e a saúde do diretor de escola no contexto das políticas educacionais no Estado do Acre" e "O trabalho docente nos municípios do Estado do Acre: políticas de formação, remuneração, carreira e condições de trabalho". 
financeiros e humanos e que tem tido tanta repercussão junto aos sujeitos que atuam no chamado “chão da escola".

O uso de provas como instrumento de incentivo para melhoria do desempenho de professores vem ganhando força e teve sua prática ampliada principalmente na última década. $\mathrm{O}$ desenho de programas de bônus para professores com desempenho diferenciado, visando estimular a melhoria na aprendizagem dos alunos, foi adotado por diferentes governos, incluindo sete estados brasileiros que já implantaram este tipo de política: Amazonas, Ceará, Espírito Santo, Minas Gerais, Pernambuco, Rio de Janeiro e São Paulo (BROOKE 2011).

Um outro estudo que merece destaque foi o realizado por Nogueira et al (2013) que fez um levantamento com base em informações disponíveis nos sítios das 27 secretarias estaduais de educação dos estados brasileiros que utilizam algum mecanismo de pagamento de bônus aos seus profissionais. A conclusão do estudo aponta que a tendência predominante nas políticas de avaliação docente se dá na perspectiva da responsabilização, na maioria das vezes utilizando-se dos resultados de avaliações do desempenho de alunos.

Por sua vez Freitas (2012) ao analisar as políticas de pagamento de bônus nas últimas décadas focou sua discussão no que ele chama de categorias centrais que irão definir a política, o que envolve uma combinação de responsabilização, meritocracia e privatização. No seu estudo o autor privilegia a produção norte americana, onde tais medidas foram largamente testadas e faz um alerta sobre "os riscos destas políticas que estão crescendo ao nível principalmente das secretarias estaduais e municipais de educação". (FREITAS, 2012, p. 379).

No caso do Estado do Acre, situamos a concepção desta política em estreita relação com a chamada Reforma do Estado Brasileiro e a defesa de uma Nova Gestão Pública (NGP), impulsionada a partir da década de 1990, principalmente no Governo de matriz neoliberal de Fernando Henrique Cardoso (1995-2002), apresentando continuidade em aspectos concernentes às relações entre avaliação e gestão em governos de cunho mais populares, a exemplo de Luis Inácio Lula da Silva (2003-2010) e Dilma Rousseff (2011-2016), que assumiram uma agenda a qual Oliveira (215) ressalta que apesar dos avanços conquistados na ampliação de direitos, diminuição da pobreza e maior inserção social, não romperam a racionalidade anterior, o que instaura contradição fundamental no setor educacional.

As Reformas do Estado abrangem um conjunto de mudanças que vêm ocorrendo tanto no que se refere à sua atuação e atribuições no campo econômico e social quanto na organização/administração das instituições por meio das quais atua no campo das políticas públicas, 
implicando em transformação do funcionamento da burocracia estatal. É nesse contexto que se insere, no âmbito da administração pública, a perspectiva de "um Estado mais enxuto e mais eficiente, que prestará um serviço de melhor qualidade aos cidadãos”. (BRESSER PEREIRA, 1998, p. 341).

O paradigma gerencial vem substituindo gradativamente os modelos burocráticos de gestão, trazendo modificações em todos os setores sociais. É exatamente isso que mostra os estudos que Stephen Ball realizou junto ao sistema de ensino do Reino Unido, onde foram enfatizados seus reflexos nos aspectos relacionados ao profissionalismo e à identidade dos trabalhadores docentes. Os estudos de Ball mostram o surgimento do gerencialismo como um mecanismo central da reforma política e da reengenharia cultural do setor público nos países do norte nos últimos vinte anos. Para o autor, o gerencialismo tem sido o "principal meio pelo qual a estrutura e a cultura dos serviços públicos são reformadas" (BALL, 2005, p.544).

A concepção de modernização da gestão vem sendo introduzida no âmbito das reformas educacionais como uma estratégia fundamental para garantir o sucesso escolar. A gestão baseada nos resultados e nos indicadores de desempenho constitui-se em um fator crucial da modernização da gestão educativa. Essa concepção tem-se fortalecido no Brasil, a partir da última década do século XX e nestes anos do século XXI. Em todo o setor público, passa-se a admitir o modelo de gestão descentralizada, com participação dos usuários/clientes dando surgimento à formulação de propostas para o desenvolvimento da gestão educacional.

Os organismos internacionais tiveram papel importante na difusão do consenso de um novo modelo de gestão no início da década de 1990 e nos anos seguintes, evidenciando em suas propostas o reconhecimento de que, à semelhança do que ocorre nos demais setores públicos, existe a necessidade de mudar o estilo burocrático de administração educacional, centralizado na figura do gestor, baseado em um conjunto de normas e funções organizadas hierarquicamente e que não responde mais às exigências da globalização e do desenvolvimento, pelo contrário, tem sido responsabilizado pelos fracassos existentes no campo educacional.

Algumas propostas da Nova Gestão Pública (NGP) estão presentes na gestão educacional, como a descentralização numa concepção que enfatiza ganhos de eficiência e efetividade, reduz custos e aumenta o controle e a fiscalização dos cidadãos sobre as políticas públicas, além de desresponsabilizar o Estado de parte de suas obrigações com os serviços sociais. Esse entendimento sobre o processo de descentralização utilizado na gestão escolar é criticado por autores, como 
Casassus (2001), tendo em vista que, na verdade, não há um real processo de descentralização, mas sim de desconcentração das responsabilidades.

Afonso (2009) faz uma contundente crítica a accountability baseada em testes estandardizados e rankings escolares e alerta que não é possível mensurar e comparar tudo em educação. O autor se detém ao contexto português e americano, contudo, é possível enxergar elementos que tem semelhanças com o que vem acontecendo no Brasil como é o caso da política de pagamento de bônus. O autor não é contra a prestação de contas, defende, contudo que para salvaguardar direitos fundamentais, precisa prever procedimentos democráticos, garantir o direito à informação e à transparência (AFONSO, 2009).

Às definições de qualidade e finalidade da avaliação, podem-se acrescentar às modalidades de responsabilização nos sistemas educacionais. Segundo Brooke (2006), pode-se caracterizar três formas ou modalidades de responsabilização, as quais são diferenciadas de acordo com as instituições que as aplicam e com o comportamento exigido. A primeira forma é denominada como burocrática. Esta procura a conformidade com as normas legais ditadas pela rede de ensino na qual o professor trabalha, e ele é responsabilizado pelo cumprimento das leis perante a burocracia que o contratou. A segunda forma indica a exigência de um comportamento profissional em conformidade com as normas formais e informais estabelecidas pelos colegas de profissão. Assim, o professor é responsabilizado pela manutenção dos padrões da profissão perante seus pares. Na terceira modalidade, a responsabilização tem como base os resultados da escola. Nela, o educador é responsabilizado perante as autoridades e o público em geral pela aprendizagem dos alunos. Além disso, as consequências, reais ou simbólicas, são associadas às medidas usadas para aferir o desempenho dos alunos.

Os efeitos dessas reformas enfatizam o papel do diretor/gestor como liderança estratégica para a eficiência e a eficácia da escola e a responsabilização da unidade escolar pelos resultados obtidos. Como consequência, no Brasil houve o estímulo de experiências de pagamento de bônus, premiação de estudantes, professores e/ou diretores pelo desempenho dos seus alunos ou de suas escolas.

No Estado do Acre foram os governos de orientação mais "popular e democrática"5 que instituíram a política de bônus. De início a política não estava vinculada ao cumprimento de metas, mas ao longo de sua trajetória outras exigências se interpuseram, sendo reveladas cobranças e uma

\footnotetext{
5 A política de Bônus foi instituída pelo Governo Arnóbio Marques Junior (2007-2010) do Partido dos Trabalhadores (PT), sofrendo alterações pelo governo atual Sebastião Viana (2011-2018) do mesmo partido político.
} 
preocupação exacerbada por resultados. Assim, os prêmios passaram a ser usados como uma técnica para camuflar baixos salários e amenizar as reivindicações dos sindicatos $^{6}$ por uma política de valorização docente mais digna.

\section{O BÔNUS E SEUS INSTRUMENTOS NORMATIVOS: IMPLEMENTAÇÃO}

A institucionalização da Política de Pagamento de Bônus na rede acriana de ensino teve início por meio da Lei Complementar $\mathrm{n}^{\circ}$ 199, de 23 de julho de 2009, que altera a Lei Complementar $n^{\circ}$ 67, de 29 de junho de 1999 - Lei que institui o Plano de Cargos, Carreira e Remuneração dos Profissionais do Ensino Público Estadual, acrescendo o art. 23-A. O dispositivo prevê o pagamento de Prêmio Anual de Valorização e Desenvolvimento Profissional - PAVDP, aos professores do quadro de pessoal da Secretaria de Estado de Educação - SEE.

A regulamentação do Prêmio, assim como as condições para seu pagamento se deu pelo Decreto $n^{\circ} 4.923$ de 30 de dezembro de 2009. Dentre outras questões, o Decreto prevê o pagamento do prêmio para os professores do quadro de pessoal da Secretaria de Estado de Educação - SEE que estejam em efetiva regência no sistema público de educação, entendida como a lotação integral e ininterrupta na sala de aula, no semestre de pagamento do Prêmio.

O regulamento estabelece que o Prêmio é composto de uma parte fixa e uma parte variavel, sendo respectivamente correspondente a $20 \%$ e $80 \%$ do valor total do prêmio. Estabeleceu os seguintes critérios como fator de mensuração para fazer jus ao recebimento do prêmio a saber: a parte fixa será paga a todos os professores em efetiva regência e a parte variável será resultante do alcance de metas que envolvem três fatores de mensuração: o primeiro diz respeito ao cumprimento da jornada escolar dentro do calendário letivo da unidade de ensino, o segundo participação nos programas de formação continuada eferecidos pela Secretaria de Estado de Esducação - SEE e o terceiro e último, cumprimento das horas de atividades previstas no planejamento da unidade de ensino. (ACRE, 2009).

No mesmo ano em que foi instituído o PAVDP, por força da Lei Complementar $n^{\circ} 204$, de 30 de dezembro de 2009, nova alteração foi realizada na Lei Complementar no 67, de 29 de junho de 1999, e foi criado o Premio Anual de Valorização e Desenvolvimento da Gestão - PAVDG,

\footnotetext{
${ }^{6}$ As últimas greves dos profissionais da educação no Estado do Acre tiveram como um dos principais pontos de reivindicação o pagamento do bônus, conhecida como VDP, principalmente a ocorrida em junho de 2016.
} 
fazendo jus a esse prêmio as equipes gestoras ${ }^{7}$ do quadro de pessoal da SEE - Secretaria de Estado de Educação.

Assim, a politica de pagamento de bônus implementada no Estado do Acre a partir de 2009, tinha como destinatários professores e equipe gestora, sujeitos essenciais no processo de reforma da educação.

A lei que instituiu o Premio Anual de Valorização e Desenvolvimento da Gestão PAVDG, inicialmente não previu critérios para o recebimento do prêmio e forma de pagamento, apenas estabeleceu um teto máximo para o recebimento do prêmio por função, ou seja, para diretores os valores máximos não podiam ultrapassar a quantia de $\mathrm{R} \$ 4.673,00$ (quatro mil, seiscentos e setenta e três mil reais, $R \$ 2.600,00$ (dois mil e seiscentos reais) para os coordenadores de ensino e $\mathrm{R} \$ 1.200,00$ (um mil e duzentos reais) para os coordenadores administrativos. Também estabeleceu que o prêmio devesse ser pago em duas parcelas, uma em julho e outra em dezembro.

Sobreveio posterior a Lei que institui o Prêmio PAVDG, o Decreto $\mathrm{n}^{\mathrm{o}} 4.924$, de 30 de dezembro de 2009 que passou a regulamentar o prêmio nos seguintes termos: a composição do prêmio em duas partes sendo uma fixa e uma variável, tal e qual o prêmio destinado aos professores e pagamento em duas parcelas semestrais, sendo uma em julho e a outra em dezembro. A condição para pagamento da parte fixa é o cumprimento de no mínimo, 90\% (noventa por cento) das metas estabelecidas pela escola na elaboração de seu Plano de Desenvolvimento - PDE. (ACRE, 2009).

Já a parte variável do Prêmio PAVDG é resultante do atingimento das seguintes metas: cumprimento da carga horária e dias letivos previstos na legislação, cumprimento dos prazos legais no tocante às prestações de contas e censo escolar e por fim, garantia da atualização das informações no sistema de gerenciamento (SIGE) da SEE.

Em 2010, foi editado novo decreto de regulamentação do Prêmio Anual de valorização e Desenvolvimento Profissional- PAVDP, Decreto $\mathrm{n}^{\mathbf{0}}$ 5.592/2010, de 15 de agosto de 2010, nos mesmos termos do Decreto $\mathrm{n}^{\mathrm{o}} 4.923$ de 30 de dezembro de 2009, apresentando como única alteração os percentuais equivalente a composição da parte variável e fixa do Prêmio, que antes era de $20 \%$ e $80 \%$ respectivamente, ficando a partir do novo decreto a $50 \%$ cada uma.

\footnotetext{
${ }^{7}$ A Equipe Gestora da Escola no Estado do Acre por força da Lei que dispõe sobre a Gestão Democrática do Sistema de Ensino Público do Estado do Acre (Lei 1.513/03) era composta por um Núcleo Gestor reunindo o Diretor, Coordenador de Ensino e Coordenador Administrativo. No ano de 2016 essa Lei foi revogada e em seu lugar passou a viger a Lei 3.141/2016. Nessa o Núcleo de Gestão foi acrescido do Coordenador Pedagógico e Secretário Escolar.
} 
O percurso legal da Política de Pagamento de Bônus no Estado do Acre, reflete de certo modo o resultado das negociações feitas entre governo, sindicatos e entidades representativas da classe dos trabalhadores em educação, resultando numa série de alterações legais para estender o prêmio a todos os trabalhadores em educação.

É o que se verifica na Lei Complementar $n^{\circ} 266$, de 29 de agosto de 2013, que estende o Prêmio PAVDP aos professores temporários, e aos professores e especialistas em educação que estejam no exercício da função de coordenador pedagógico nas unidades de ensino.

A regulamentação do prêmio para os coordenadores pedagógicos foi feita por meio do Decreto $\mathrm{n}^{\circ}$ 6.263, de 10 de agosto de 2013, nos mesmos moldes dos demais decretos, diferenciandose apenas no que diz respeito ao percentual da parte fixa e variável do prêmio, que neste foi estabelecido em $20 \%$ e $80 \%$ respectivamente, e quanto aos critérios de atingimento das metas, o regulamento estabelece os seguintes: ter executado, no mínimo, 90\% do plano de trabalho bimestral da coordenação pedagógica aprovado pelo diretor da escola, ter executado plano de ação bimestral para a melhoria da aprendizagem dos alunos de baixo rendimento com base nas avaliações internas e externas e ter realizado a avaliação dos resultados das ações desenvolvidas pela unidade escolar no semestre e propor ações de intervenção. (ACRE, 2013).

Por fim em 2014, por meio da Lei Complementar no 285 de 11 de abril de 2014, o prêmio foi também estendido aos não docentes efetivos ou temporários em exercício nas unidades escolares e administrativas da Secretaria de Estado de Educação - SEE.

Neste mesmo ano, o governo editou um decreto de $n^{\circ} 8.674$, de 21 de novembro de 2014, que efetuou alterações nos decretos 5.592/2010, 4.924/2009 e 6.263/2013, respectivamente referente ao Prêmio VDP para professores do quadro da SEE, Prêmio VDG para a equipe gestora das unidades escolares e Prêmio VDP para coordenadores pedagógicos. As alterações referem-se unicamente ao pagamento da segunda parcela previstas para dezembro, ficando então alterada para recebimento em janeiro do ano subsequente ao alcance das metas, apuradas no período de julho a dezembro.

O decreto 3.191/2015 trouxe algumas alterações substanciais, dentre as quais destaca-se: a periodicidade para aferição do prêmio que passa a ser de um ano letivo, a unicidade do pagamento que passou a ser pago em única parcela e o prazo limite para o pagamento, que é até o final do mês de junho do ano subsequente à avaliação. (ACRE, 2014).

As mudanças que foram implementadas a partir do decreto 3.192/2015, alteraram não só a sistemática de pagamento do prêmio, como também estabeleceu novos critérios de aferição e 
definiu metas que foram vinculadas ao Índice de Desenvolvimento da Educação do Acre - IDEA, criado à semelhança do IDEB - Índice de Desenvolvimento da Educação Básica, nacionalmente.

No que se refere aos requisitos para habilitação ao recebimento do prêmio, estes foram definidos de acordo com cada categoria de servidor, no entanto, o decreto define requisitos gerais, e de acordo com cada categoria de servidor, critérios adicionais.

Como critério geral, a norma estabelece que a escola deve ter o seu Projeto Político Pedagógico protocolado e/ou aprovado pelo Conselho Estadual de Educação, ter o Plano de Desenvolvimento da Escola aprovado pela SEE, ter os dados do Sistema de Monitoramento e avaliação Educacional - SIMAED atualizados até o dia 31 de dezembro do ano de aferição do prêmio, ter cumprido o mínimo de 200 dias de efetivo trabalho escolar e 800 horas aulas previstas no calendário escolar aprovado pela SEE, para o ano letivo em aferição, ter cumprido os prazos definidos para a realização do Censo Escolar e ter a prestação de contas dos programas de descentralização de recursos protocoladas e/ou aprovadas pela SEE conforme lei vigente. (ACRE, 2015).

Os critérios adicionais, para que os servidores lotados nas escolas estejam habilitados a receber o prêmio, ficam assim estabelecido: a) para professores e coordenadores cumprimento da jornada escolar, das horas de planejamento e participação nos programas de formação continuada oferecidos pela SEE; b) para não docentes $100 \%$ de frequência laboral e c) para a equipe gestora os critérios estão vinculados a elevação da elevação da proficiência das escolas em relação ao SEAPE, elevação ou manutenção dos padrões para as escolas que se encontram no padrão avançado.(ACRE,2015).

Para os servidores lotados nas unidades administrativas da SEE e representações nos municípios, os critérios se restringem a $100 \%$ de frequência laboral e apresentação de relatórios anuais de atividades executadas, tudo no período de apuração do prêmio. (ACRE, Art. 5, 2015).

Além dos pré-requisitos e dos critérios adicionais estabelecidos no regulamento, o pagamento do Prêmio VDP foi condicionado ao atingimento das metas do Índice de Desenvolvimento da Educação do Acre - IDEA, ficando definido dois grupos de metas: metas para as escolas mistas e metas para as unidades administrativas e representações da SEE nos municípios.

Quanto ao cumprimento das metas, o decreto 3.190/2015 estabelece uma escala, tanto para as unidades escolares em que os servidores estiverem lotados como para os lotados nas unidades administrativas. A escala estabelecida para as unidades escolares são as seguintes: para as escolas que atingirem de 91 a $100 \%$ das metas do IDEA, será aplicado o percentual de $100 \%$ e para as 
escolas que atingirem de $81 \%$ a $90 \%$ das metas do IDEA, será aplicado o percentual de $90 \%$. (ACRE, 2015).

Já para os servidores lotados nas unidades administrativas, a escala a ser observada é a referida no $\S 2^{\circ}$ do Art. $8^{\circ}$, a saber: será aplicado o percentual de $100 \%$ se o Estado atingir ou superar as metas do IDEA para cada etapa de ensino, de $90 \%$ se atingir de $90 \%$ a $99 \%$ e por fim, se o Estado atingir em menos de $90 \%$ em quaisquer etapas avaliativas, os servidores não farão jus à premiação. (ACRE, 2015).

Por fim o Decreto 3.190/2015 cria duas comissões: Comissão Estadual de Acompanhamento do Prêmio VDP e Comissão de Avaliação do Prêmio VDP. A primeira é constituída de dois representantes da Secretaria de Estado de Educação e Esportes - SEE, um representante do Sindicato dos Trabalhadores em Educação do Acre - SINTEAC, um representante do Sindicato dos Professores Licenciados - SINPLAC e um representante do Colegiado de Diretores de Escolas Públicas - CODEP. A segunda Comissão constituída somente por servidores da SEE, cujos procedimentos e mecanismos de avaliação e controle necessários a implementação do Prêmio VDP é feito por ato do Secretário (ACRE, 2015).

O pagamento do Prêmio VDP dos anos de 2017 referente ao ano de aferição de 2016 foi suspenso, por força da negociação ${ }^{8}$ entre governo e sindicatos, no entanto, será novamente pago em junho deste ano (2018) correspondente a aferição realizada em 2017.

$\mathrm{Da}$ analise especialmente do Decreto $\mathrm{n}^{\mathrm{o}} 3.190 / 2015$ que passou a regulamentar definitivamente o prêmio VDP, é possível destacar alguns aspectos marcantes da política de bonificação acriana. Em primeiro lugar, o texto da norma explicita claramente a preocupação do governo com a elevação dos índices educacionais do estado, quando condiciona o recebimento do prêmio ao atingimento das metas do IDEA, o que torna o prêmio um elemento catalisador de uma gestão por resultados.

A esse respeito Nogueira (2015) ao analisar o Sistema de Avaliação da Educação Básica do Acre (SEAPE/AC) destaca que a avaliação em larga escala adotada também na rede acriana, por

\footnotetext{
${ }^{8}$ A negociação refere-se a proposta de adoção do piso nacional dos professores para os trabalhadores em educação, sob a condição de que o pagamento da VDP fosse suspenso por dois anos de forma a criar condições financeiras de implantar o piso nacional de $\mathrm{R} \$ 2.402,60$ de forma parcelada. A proposta foi aceita pelos professores, ficando acordado que o piso seria pago em três parcelas, sendo duas no ano de 2017 e uma em 2018, bem como a suspensão do pagamento da VDP por dois anos, devendo retornar em 2018.
} 
meio do SEAPE/AC, constitui um eixo orientador na definição das políticas educacionais, visando à eficiência e a produtividade.

É, portanto, o que se observa na definição do Prêmio VDP, que constitui a política de bonificação do estado. Inicialmente, concebido para garantir a permanência do docente em sala de aula, já que condicionava o recebimento do prêmio apenas à efetiva regência em sala de aula, passa posteriormente a se vincular, especialmente ao atingimento das metas do índice de desenvolvimento da educação acriana, perdendo a características de incentivo e/ou valorização docente e passando a constituir-se no que Nogueira (2015) chama de "prêmio por resultados".

As metas para aferição e recebimento do prêmio VDP instituídas no último decreto regulamentador, definem as "regras do jogo" e impõem um tipo de cultura, agora voltada exclusivamente para conceitos como eficiência e produtividade numa perspectiva empresarial.

Os prêmios e bônus constituem mecanismos de coordenação indireta, formas que os governos utilizam para regular o trabalho da escola e do professor, com certo autoritarismo sem parecer fazê-lo, uma espécie de monitoramento a distância que faz com que o Estado "se insira profundamente nas culturas, práticas e subjetividades das instituições do setor público e de seus trabalhadores". (BALL, 2004, p.1116).

Essa inserção invisível do estado que capta a subjetividade do servidor, especialmente do professor e demais profissionais da educação é o que Ball (2004) chama de performatividade. "Ela objetifica e mercantiliza o trabalho do setor público, e o trabalho com conhecimento (knowledgework) das instituições educativas transforma-se em "resultados”, "níveis de desempenho", "formas de qualidade". [...]. (BALL, 2004, p.1116).

Os desdobramentos das políticas de bônus ou prêmios geram uma serie de consequências para o processo ensino-aprendizagem, para o professor e para a escola. No que se refere ao processo de ensinar e aprender, este pode ser reduzido a um treino, onde o aluno deve apresentar o comportamento esperado e desejado nos testes e exames padronizados.

O professor pode ter sua subjetividade ameaçada, o que poderá levá-lo a conduzir o seu fazer a partir dos resultados que deve apresentar, sob pena de sanção, que em alguns modelos como o Americano chegava a demissão. Associado a isso, outros valores e práticas são agregados como, por exemplo, as fraudes, ao que parece muito comum nos modelos adotados por diversos estados brasileiros. 
Por fim, a escola também sofre as consequências uma vez que os prêmios ou bônus se constituem numa espécie de certificação e classificação que fazem com que, a partir da divulgação dos resultados, seja classificada em boas e ruins, atraindo ou afastando seu público alvo.

No caso do Estado do Acre, não se tem ainda pesquisas concluídas que apontem os efeitos da bonificação, tanto do ponto de vista da responsabilização como no sentido de ter sido decisivo para a elevação dos índices educacionais do Estado, contudo, já existem estudos em processo de construção que focam o processo de concepção e implementação da política, bem como seus desdobramentos práticos. Espera-se que esses estudos possam ser reveladores de elementos mais consistentes, o que nos permitirá com base na empiria fazer uma análise mais circunstanciada da política e seus desdobramentos/alcance junto aos seus beneficiários componentes do magistério público da rede acriana de educação básica.

\section{CONCLUSÕES}

Durante este estudo procurou-se revelar, como modelos e políticas de gestão, ancoradas numa concepção privatista e gerencialista que se voltam para o lucro, têm sido cada vez mais importados para a administração pública brasileira, principalmente a partir de 1995, com a Reforma Gerencial do Estado, impulsionada pela racionalidade de uma Nova Administração Pública e seu modus operandi. No rastro dessas políticas, diversos estados e municípios brasileiros já utilizam a remuneração por desempenho dos professores e demais profissionais que compõem o quadro do magistério.

Tem sido este também o rumo adotado pelas políticas educacionais em curso no Estado do Acre. Mesmo reconhecendo que ainda carecemos de maiores estudos empíricos que possam avaliar os impactos desta política no processo de construção de novas subjetividades, se de fato se constituem em instrumentos de controle e de culpabilização dos profissionais do magistério acriano pelos resultados educacionais, já é possível afirmar que tal política tem gerado uma série de conflitos entre governo, sindicatos e profissionais da educação. As últimas greves do magistério nesse estado são reveladoras de parte dessas questões.

Assim em uma análise preliminar, dessa política, depreende-se que a concepção que a orienta se dá na perspectiva de responsabilização do professor e demais profissionais da educação acriana, promovendo um processo que não tem contribuído, explicitamente, para o desenvolvimento da carreira docente, ao contrário tem contribuído para sua segmentação e conflitos. Dessa forma, somos levadas a corroborar com a opinião de Freitas (2012) de que essa 
política de bônus copiada do modelo americano, onde fracassou, apresenta riscos para os sistemas de ensino, não sendo diferente no Estado do Acre que igual assinalado em outros sistemas, já é possível perceber alguns destes riscos como o estreitamento curricular, a competição entre os profissionais e escolas, a pressão sobre os alunos e professores, dentre outros.

Embora se reconheça que foi com a gestão dos governos da Frente Popular iniciada ainda em 1999, com a gestão do então governador e hoje Senador Jorge Viana, que políticas de maior alcance privilegiaram o magistério, caminhando no sentido de lhes garantir um mínimo de dignidade, não devemos deixar de registrar que foram esses mesmos governos que durante o processo de governança foram perdendo de vista outras racionalidades, outras concepções, outras práticas pedagógicas que poderiam muito bem presidir todo esse percurso numa linha mais democrática e menos gerencial.

A busca pela eficiência e por resultados não pode se sobrepor aos mecanismos de participação e a valorização docente. Essa é uma política economicista e meritocrática que procura se inspirar em aspectos que caracterizam o funcionamento da iniciativa privada aplicando-o na escola pública. Esta lógica em última instância joga nos ombros dos profissionais da escola à responsabilidade pelos resultados educacionais, independente das condições de trabalho dadas. Associa-se a essas características a ampla divulgação dos resultados das avaliações na mídia, usualmente na forma de classificação das instâncias avaliadas, induzindo à comparação, em nome da necessidade de prestação de contas à sociedade. Políticas educacionais formuladas e implementadas sob a égide da meritocracia e da privatização carregam consigo, consequentemente, a exclusão, como inerente aos seus resultados, o que é incompatível com à ampliação do direito à educação pra todos. 


\section{REFERÊNCIAS}

ACRE. Lei Complementar $\mathbf{n}^{\mathbf{0}}$ 199, de 23 de julho de 2009. Altera as Leis ns. 1384, de 24 de maio de 2001; 1.394, de 28 de junho de 2001; 1.704 , de 26 de janeiro de 2006; 1.907, de 24 de julho de 2007; 1.956 , de 04 de dezembro de 2007, e as Leis Complementares ns. 67, de 29 de junho de 1999; 84, de 28 de fevereiro de 2000; 102 , de 26 de dezembro de 2001 e 167, de 24 de julho de 2007. Disponível em: 〈http://www.diario.ac.gov.br> Acesso em: 10 de fevereiro de 2017.

ACRE. Lei Complementar $\mathbf{n}^{\mathbf{0}}$ 204, de 30 de dezembro de 2009. Altera e acresce dispositivos da Lei Complementar n. 67, de 29 de junho de 1999, que dispõe sobre o Plano de Cargos, Carreira e Remuneração dos Profissionais de Ensino Público Estadual e dá outras providencias. Disponível em: <http://www.diario.ac.gov.br> Acesso em: 10 de fevereiro de 2017.

ACRE. Lei Complementar $\mathbf{n}^{\mathbf{0}} \mathbf{2 6 6}$, de 29 de agosto de 2013. Altera a Lei Complementar n. 67, de 29 de junho de 1999 , que dispõe sobre o plano de cargos, carreira e remuneração dos profissionais do ensino público estadual. Disponível em: <http://www.diario.ac.gov.br> Acesso em: 14 de fevereiro de 2017.

ACRE. Lei Complementar $\mathbf{n}^{\mathbf{0}}$ 285, de 11 de abril de 2014. Altera dispositivos da Lei Complementar n. 67, de 29 de junho de 1999, que dispõe sobre o plano de cargos, carreira e remuneração dos profissionais do ensino público estadual e dá outras providencias. Disponível em: 〈http://www.diario.ac.gov.br〉 Acesso em: 14 de fevereiro de 2017.

ACRE. Decreto $\mathbf{n}^{\mathbf{0}}$ 4.923, de 30 de dezembro de 2009. Regulamenta o Premio de Valorização e Desenvolvimento Profissional - VDP, de que trata o art. 23-A da Lei Complementar no 67, de 29 de junho de 1999. Diário Oficial do Estado do Acre, Ano XLII, no 10.204, de 31 de dez de 2009, p. 128.

ACRE. Decreto $\mathbf{n}^{\mathbf{0}}$ 4.924, de 30 de dezembro de 2009. Regulamenta o Premio de Valorização e Desenvolvimento da Gestão - VDG, de que trata o art. 23-B da Lei Complementar n ${ }^{\circ}$ 67, de 29 de junho de 1999. Diário Oficial do Estado do Acre, Ano ...., no 10.204, de 31 de dez de 2009, p. 129.

ACRE. Decreto $\mathbf{n}^{\mathbf{0}}$ 5.592, de 16 de agosto de 2010. Regulamenta o Prêmio Anual de valorização e Desenvolvimento Profissional - PAVDP, de que trata o art. 23-A, da Lei Complementar n ${ }^{\circ}$ 67, de 29 de junho de 1999. Disponível em: <http://www.diario.ac.gov.br> Acesso em: 13 de fevereiro de 2017.

ACRE. Decreto $\mathbf{n}^{\mathbf{0}} \mathbf{6 . 2 6 3}$, de 19 de agosto de 2013. Regulamenta o Premio de Valorização e Desenvolvimento Profissional - VDP, de que trata o art. 23-C da Lei Complementar $n^{\circ}$ 67, de 29 de junho de 1999. Diário Oficial do Estado do Acre, Ano XLVI, no 11.117 , de 22 de ago de 2013, p. 1-2.

ACRE. Decreto $\mathbf{n}^{\mathbf{0}} \mathbf{8 . 6 7 4}$, de 21 de novembro de 2014. Altera os Decretos nos 5.592, de 16 de agosto de 2010; 4.924, de 30 de dezembro de 2009 e 6.263, de 19 de agosto de 2013, que regulamentam, respectivamente, o Prêmio Anual de Valorização e Desenvolvimento Profissional (VDP), o Prêmio Anual de Desenvolvimento da Gestão (VDG) e o Prêmio Anual de Desenvolvimento de Desenvolvimento Profissional (VDP) para os Coordenadores Pedagógicos Diário Oficial do Estado do Acre, Ano XLVII, no 11.443, de 25 de nov de 2014, p. 9.

ACRE. Decreto no 3.191, de 19 de agosto de 2015. Regulamenta o Premio de Valorização e Desenvolvimento Profissional (VDP) dos servidores da Secretaria de Estado de Educação e Esporte de que trata o art. 23-D da Lei Complementar n⿳0 67, de 29 de junho de 1999, acrescido pela Lei Complementar Estadual n²85, de 11 de abril de 2014. Diário Oficial do Estado do Acre, Ano XLVIII, n 11.623, de 20 de ago de 2015, p. 1-3.

AFONSO, A.J. Nem tudo o que conta em educação é mensurável e comparável. Crítica à accountability baseada em testes estandardizados e rankings escolares. Revista

Lusófona de Educação, Lisboa, v. 13, n. 2, 2009.

BALL, S. J. Profissionalismo, Gerencialismo e Performatividade. Cadernos de Pesquisa, v. 35, n. 126, p. 539-564, set./dez. 2005.

S. J. Performatividade, Privatização e o pós-estado do bem estar. Cadernos de Pesquisa, v.25, n.89, p. 11051126, set./dez. 2004. 
BRESSER PEREIRA, L.C. Gestão do setor público: estratégia e estrutura para um novo Estado. IN: BRESSER PEREIRA, L.C.; SPINK, P.K. (Org.). Reforma do estado e administração pública gerencial. 5. ed. Rio de Janeiro: Fundação Getúlio Vargas, 1998.

BROOKE, N. O futuro das políticas de responsabilização educacional no Brasil. Cadernos de Pesquisa, v. 36, n. 128, mai/ago, 2006. p. 377-401.

Avaliação Externa como Instrumento da Gestão Educacional nos Estados. São Paulo, Fundação Victor Civita, ago. 2011.

CASASSUS, J. A reforma educacional na América Latina no contexto da globalização. Cadernos de Pesquisa. São Paulo, n. 114, nov.2001.

FREITAS, L.C. Os reformadores empresariais da educação: da desmoralização do magistério à destruição do sistema público de educação. Educação \& Sociedade,Campinas, v. 33, n. 119, p. 379-404, 2012.

NOGUEIRA, D. X. P. et all. Avaliação de desempenho docente no Brasil: desvelando concepções e tendências. Universidade de Brasília Linhas Críticas, Brasília, DF, v. 19, n. 38, p. 13-32, jan./abr. 2013.

NOGUEIRA, R.S. Avaliação em larga escala como regulação: o caso do Sistema Estadual de Avaliação da Aprendizagem Escolar - SEAPE/ACRE. 260f. Tese (Doutorado em Educação), UFPR, Curitiba, 2015.

OLIVEIRA, D. A. Nova Gestão Pública e Governos Democrático-Populares: contradições entre a busca da eficiência e a ampliação do direito à educação. Educ. Soc., Campinas, v. 36, nº. 132, p. 625-646, jul.-set., 2015

SOUZA, S. Z.; OLIVEIRA, R. P. de. Sistemas estaduais de avaliação: uso dos resultados, implicações e tendências. Cadernos de Pesquisa, v. 40 n.141, p.793-822. 2010. 


\section{A POLÍTICA DE BÔNUS PARA OS PROFISSIONAIS DA EDUCAÇÃO NO ESTADO DO ACRE: CONCEPÇÃO E NORMATIZAÇÃO}

\section{RESUMO}

O estudo avalia a política de pagamento de bônus na educação pública e suas implicações na valorização do trabalho dos profissionais da educação básica acriana. Vincula-se aos resultados finais de pesquisa que investiga as repercussões das políticas educacionais no trabalho dos diretores e professores no Estado do Acre. É fruto de revisão de literatura e pesquisa documental, dividindo-se em dois momentos. No primeiro, discute a concepção que orienta as políticas de bônus e no segundo, examina a normatização que define critérios para sua concessão. Parte do entendimento do bônus-mérito numa visão de totalidade política em suas múltiplas dimensões. Os aspectos conclusivos do estudo revelam que o bônus se caracteriza como um instrumento de regulação na tentativa de melhoria do desempenho do sistema.

Palavras-Chave: Política Educacional; Bônus; Valorização dos Profissionais do Magistério.

\section{THE POLICY OF BONUS FOR EDUCATIONAL PROFESSIONALS IN THE STATE OF ACRE: CONCEPTION AND NORMATIZATION}

\section{ABSTRACT}

The study evaluates the bonus payment policy in public education and its implications in valuing the work of acriana basic education professionals. It is linked to the final results of research that investigates the repercussions of educational policies on the work of directors and teachers in the State of Acre. It is the fruit of literature review and documentary research, dividing into two moments. In the first, it discusses the conception that guides the policies of bonuses and in the second, it examines the normatization that defines criteria for its concession. Part of the understanding of bonus-merit in a vision of political totality in its multiple dimensions. The conclusive aspects of the study reveal that the bonus is characterized as an instrument of regulation in the attempt to improve the performance of the system.

Keywords: Educational Policy; Bonus; Valorization of the Teaching Professionals.

\section{LA POLÍTICA DE BONUS PARA LOS PROFESIONALES DE LA EDUCACIÓN EN EL ESTADO DEL ACRE: CONCEPCIÓN Y NORMATIZACIÓN}

\section{RESUMEN}

El estudio evalúa la política de pago de bonos en la educación pública y sus implicaciones en la valorización del trabajo de los profesionales de la educación básica acriana. Se enlaza a los resultados finales de investigación que investiga las repercusiones de las políticas educativas en el trabajo de los directores y profesores en el Estado de Acre. Es fruto de revisión de literatura e investigación documental, dividiéndose en dos momentos. En el primero, discute la concepción que orienta las políticas de bonos y en el segundo, examina la normatización que define criterios para su concesión. Parte del entendimiento del bono-mérito en una visión de totalidad política en sus múltiples dimensiones. Los aspectos concluyentes del estudio revelan que el bono se caracteriza como un instrumento de regulación en el intento de mejora del desempeño del sistema.

Palabras clave: Política Educativa; bonificaciones; Valorización de los Profesionales del Magisterio. 